\title{
CHEMODECTOMA (NON-CHROMAFFIN PARAGANGLIOMA) OF THE NINTH INTERCOSTAL SPACE
}

\author{
BY
}

\author{
K. M. SHAW AND J. D. KENNEDY
}

From the Thoracic Surgery Unit, St. Patrick's Chest Hospital, Castlerea, Eire

(RECEIVED FOR PUBLICATION SEPTEMBER 14, 1955)

The term chemodectoma has been introduced by Mulligan (1950) to designate tumours derived from chemoreceptor bodies and having general characteristics similar to carotid and aortic body tumours. The purpose of this report is to place on record a chemodectoma arising in relation to the ninth intercostal space.

\section{CAse Report}

In a 30-year-old man, radiography revealed a mass in relation to the ninth left intercostal space (Fig. 1). There was no radiological increase in the size of the mass one year later when operation was undertaken. At operation a sessile mass was removed from the ninth left intercostal space posteriorly, in the position usually

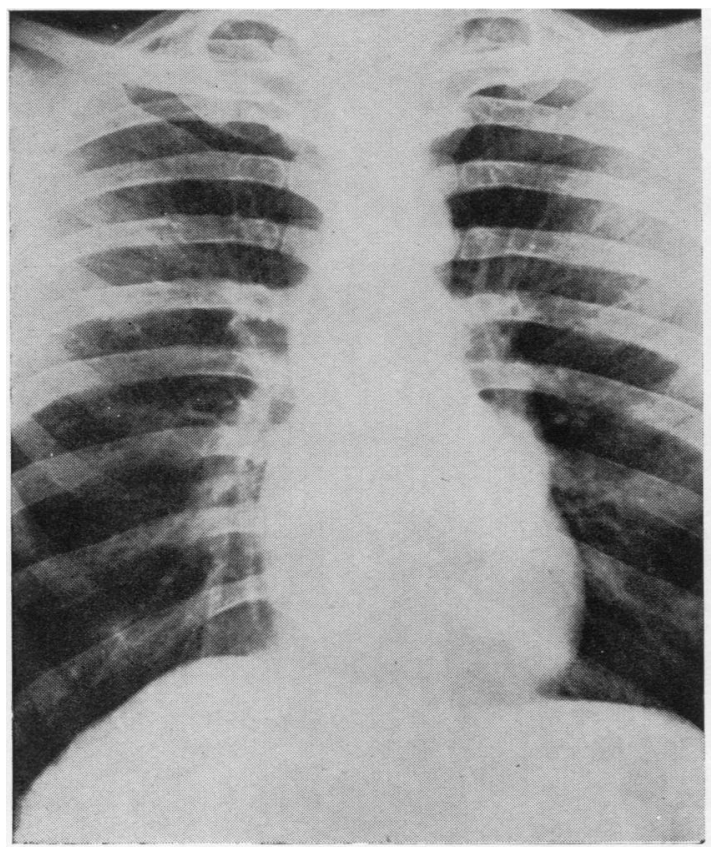

(a)

Fig. 1.-Antero-posterior and lateral radiographs showing rounded mass lying behind the heart in the left paravertebral gutter at the level of the ninth intercostal space. occupied by a neurofibroma. The tumour was thought to arise from the intercostal nerve or the sympathetic chain, though there was no obvious connexion with either.

Ten months after operation, the patient was well, without clinical or radiological evidence of recurrence.

The specimen consists of an encapsulated oval tumour mass, without lobulation, measuring 10 mm. $\times 5 \mathrm{~mm}$. (Fig. 2). The cut surface is light yellow and has a spongy texture. Histologically it shows the basic structure of a carotid body tumour. It consists of nests of pale " epithelioid" type cells surrounded by a vascular stroma. Many of the nuclei of the pale or "chief cells" are hyperchromatic and occasional multinucleated forms are

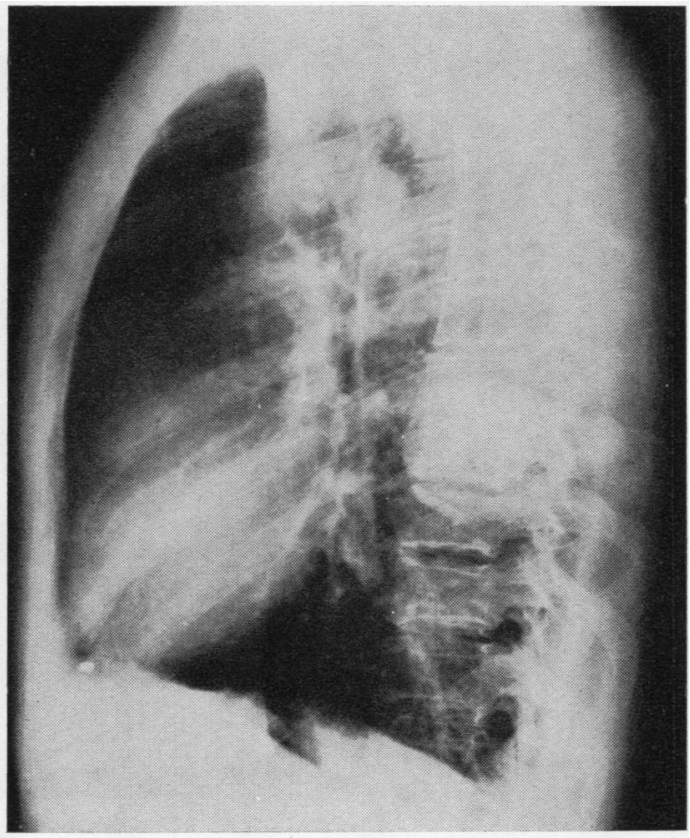

(b) 


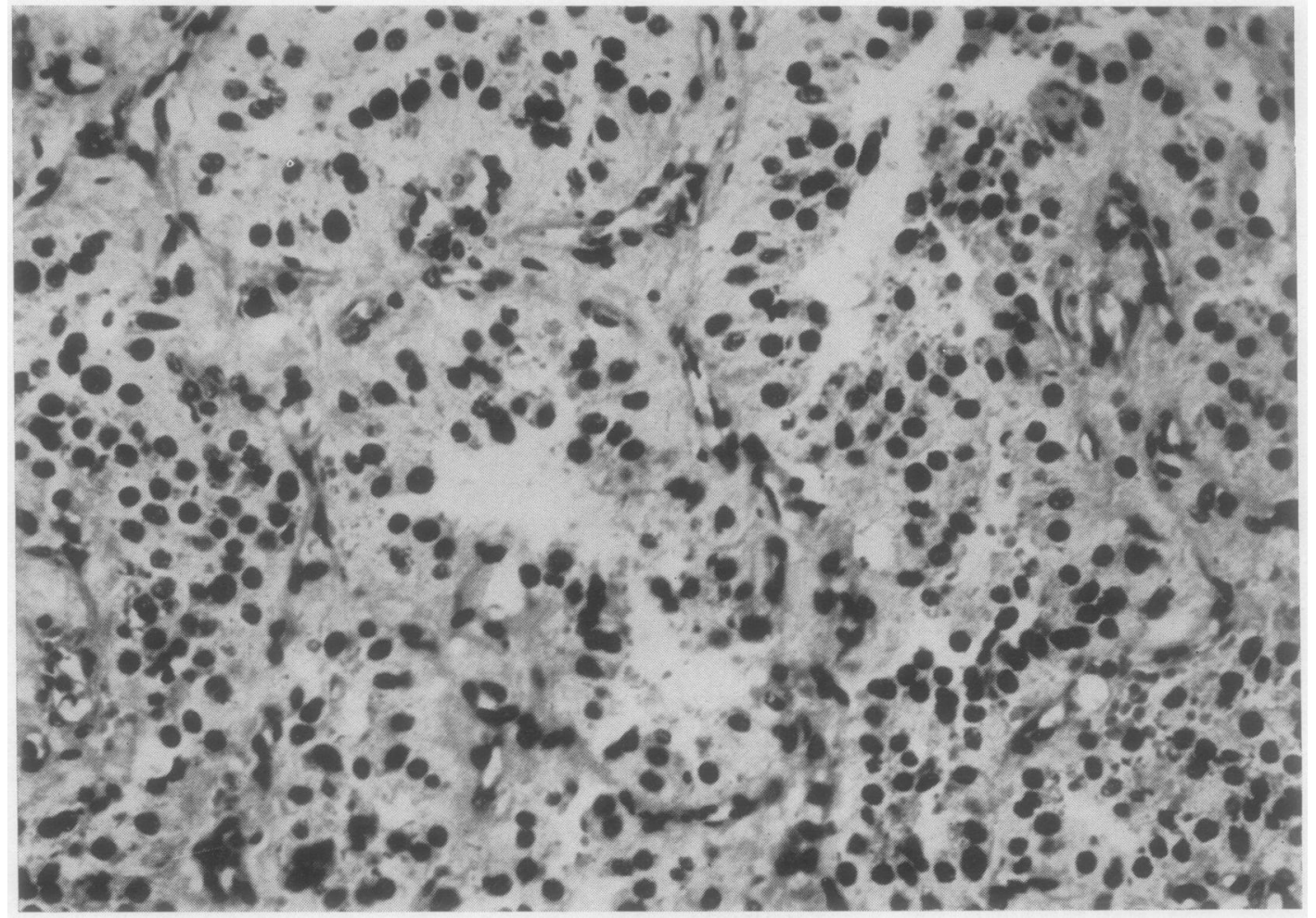

FIG. 2.-Haematoxylin and eosin preparation, $\times 300$

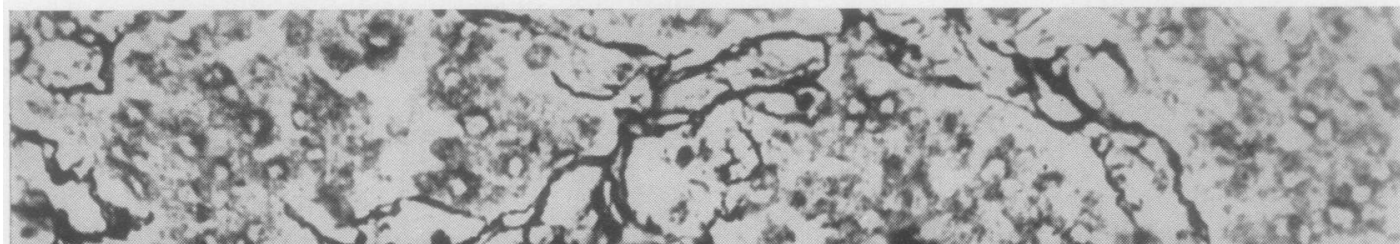
3
3

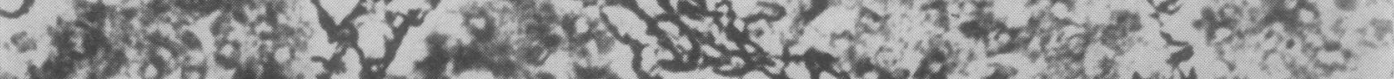

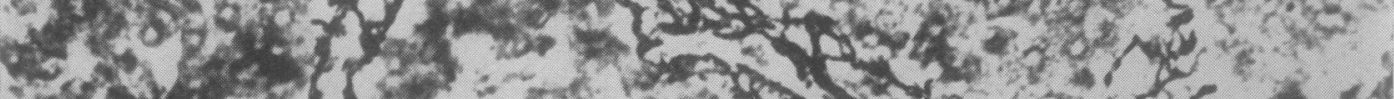

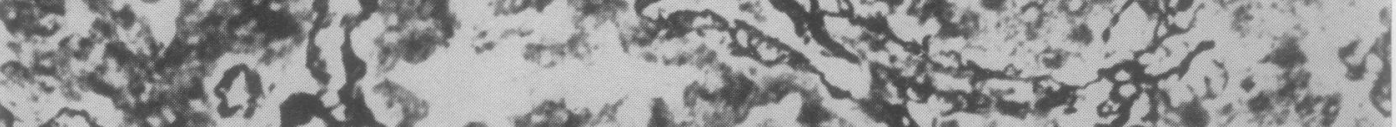
S.

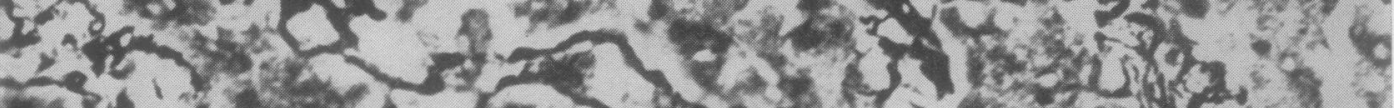

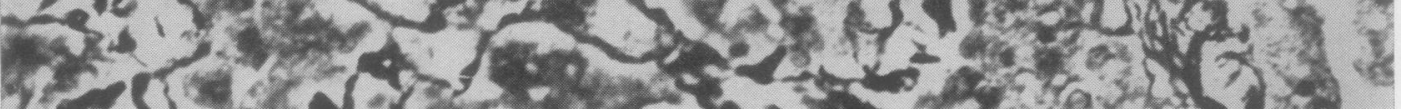
a

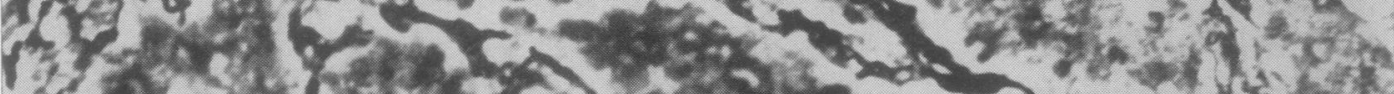

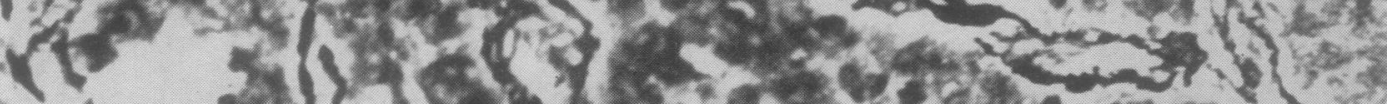

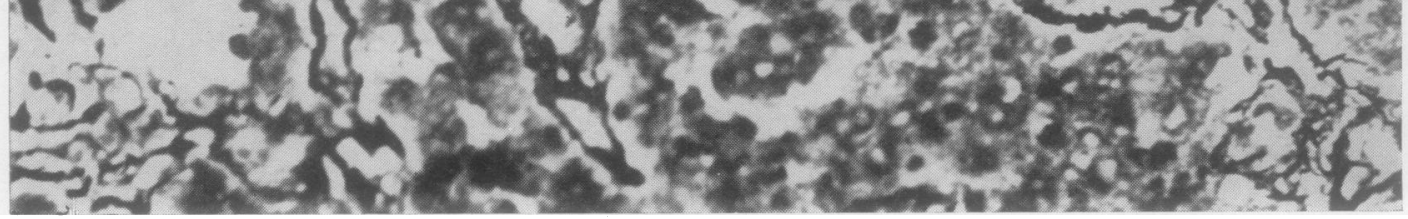




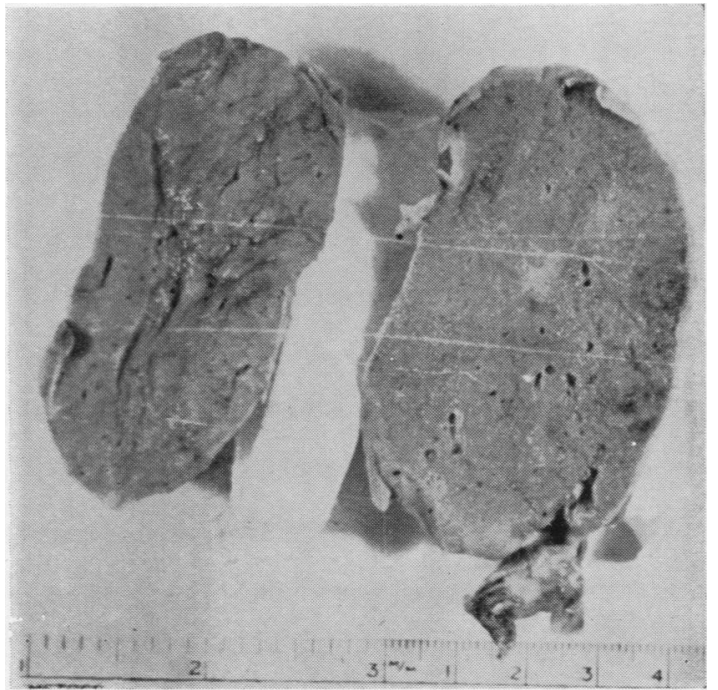

Fig. 4.-Photograph of tumour removed.

seen. This feature has been previously described in the absence of malignant behaviour (Le Compte, 1948). The pattern of the tumour in the haematoxylin-eosin-stained sections and the silver impregnation is identical with a carotid chemodectoma reported from here by McDermott (1954) and with the jugular bulb chemodectoma reported by Gaffney (1953). The tumour did not give the chromaffin reaction and its surface did not darken significantly in ageing.

\section{Discussion}

Within the mediastinum chemoreceptor bodies have been described in relation to the innominate artery, the left aortic arch, and the pulmonary trunk. Two cases of tumours apparently arising from these bodies have been described by Lattes (1950) and one by Monro (1950) in relation to these structures. Davies and Randall (1954) have described a benign aortic body tumour occurring on the anterior aspect of the pericardium. Duncan and McDonald (1951) have described two cases arising from the lower right intercostal spaces, a site in which chemoreceptor tissue has not been described. The tumour in the first case arose in the right costo-vertebral sulcus between the ninth and eleventh ribs. The location in the second case was the right costo-vertebral sulcus at the level of the sixth, seventh, and eighth ribs. Chemodectomas have now been described as occurring in the thigh, retroperitoneal tissues, and neck, one of the most recently published cases being that of Randall and Walter (1954). They describe a malignant soft tissue tumour of the thigh with evidence suggesting a chemoreceptor origin.

\section{SUMMARY}

A case of chemodectoma (non-chromaffin paraganglioma) in the left posterior mediastinum is described. It is presented as an addition to the already complex differential diagnosis of round intrathoracic densities.

\section{REFERENCES}

Davies, J. R., and Randall, K. J. (1954). J. Path. Bact., 68, 247. Duncan, D. K., and McDonald, J. R. (1951). Amer. J. clin. Path., 21, 515 .

Gaffney, J. C. (1953). J. Path. Bact., 66, 157.

Lattes, R. (1950). Cancer, 3, 667.

Le Compte, P. M. (1948). Amer. J. Path., 24, 305.

MacDermott, E. N. (1954). Brit. J. Surg., 41, 437.

Monro, R. S. (1950). Ibid., 38, 105.

Mulligan, R. M. (1950). Amer. J. Path., 26, 680

Randall, K. J., and Walter, J. B. (1954). J. Path. Bact., 67,-69. 